\title{
A new forum to spread the word on vaccine research
}

This article was published in the following Dove Press journal:

Vaccine: Development and Therapy

30 April 20II

Number of times this article has been viewed

\author{
Marcela F Pasetti \\ Center for Vaccine Development \\ Department of Pediatrics \\ University of Maryland School \\ of Medicine, 685 West Baltimore \\ St Room 480 Baltimore, \\ MD 21021 , USA
}

Correspondence: Marcela F Pasetti Center for Vaccine Development Department of Pediatrics University of Maryland School of Medicine, 685 West Baltimore St Room 480 Baltimore, MD 2102।, USA

$\mathrm{Tel}+$ I 410 706234 I

Fax +I 4107066205

E-mail mpasetti@medicine.umaryland.edu
Welcome to the first edition of Vaccine: Development and Therapy. In these exciting times where the field of vaccinology continues to advance and mature, this journal seeks to provide a venue for wider distribution of original research efforts related to vaccine development, evaluation and implementation. Studies in all disciplines that lead to new and more effective vaccine strategies to prevent diseases or to improve human health are welcomed.

Unlike any other medical intervention, vaccines have had a dramatic impact improving quality of life and promoting the wellbeing of society in general. The progress in this area over the past few decades has been unprecedented and much more is expected for the years to come. ${ }^{1}$ Modern technology and scientific breakthroughs have led to the discovery of new virulence factors and candidate vaccine antigens. They have also allowed us to devise innovative immunization strategies. Significant progress has been made deciphering cellular interactions and molecular pathways underlying the induction and regulation of immune responses. ${ }^{2}$ In addition, a better understanding of the interplay between innate and adaptive immunity has drawn our attention to the study of novel and safer adjuvants. ${ }^{3}$

Research efforts have also been directed to address the needs of special populations (i.e. newborns, very young infants and the elderly). ${ }^{1}$ There has been renewed interest in optimized immunization schedules to maximize vaccine-induced immune responses. ${ }^{4}$ Lead vaccine candidates have been readily taken into various phases of clinical trials, many of them in field settings, in target populations. A number of new vaccines have reached the market including two human papillomavirus (HPV) and rotavirus vaccines and a quadrivalent meningococcal conjugate vaccine, while some existing vaccines have been adapted for use in specific groups (e.g. acellular pertussis for adolescents and adults, and inactivated influenza for the elderly). ${ }^{1}$

Major philanthropic organizations such as the Bill and Melinda Gates Foundation and international vaccine advocates, including the Global Alliance for Vaccines and Immunizations (GAVI), have partnered, joining resources and efforts to strengthen global immunization initiatives so that vaccines can be delivered to the populations most in need. Notable investments have been made by the U.S. government to support the development of vaccines against pathogens regarded as potential bioterror threats. ${ }^{1}$ Finally, we have witnessed the powerful influence of public opinion and perception (particularly with regards to vaccine safety) in the acceptance of new vaccines ${ }^{5}$ and compliance with routine immunization programs. ${ }^{6}$ 
Vaccine: Development and Therapy aims to provide a reputable forum for scientists to convey rigorous research exploring these issues. At a time when most basic science journals tend to prioritize specific themes, emphasizing novelty and mechanistic analysis, our goal is to support high quality research addressing any aspect of vaccinology (scientific, epidemiologic, ethical, economic, etc.) with potential to advance the field, stripped of any bias or business agenda.

The primary requirement for accepting manuscripts will be scientific merit determined by peer review, striving for contributions of the highest quality. An outstanding group of editorial board members with critical expertise will assist in this endeavor. Decisions will be made promptly to speed up the publication process. Dedicated staff members from Dove Medical Press are available to diligently respond to the author's needs. The journal will seek on-line indexing through major literature databases (e.g. PubMed) as soon as it reaches the publication requirements. As time goes by, we trust that the journal will grow in character and recognition. We also seek to become a venue for training and support of the next generation of vaccinologists. This will be an exciting first year. A "golden era" is unfolding in the history of vaccinology" and looking forward to these promising times, we pledge our effort to build up an effective and suitable platform for disseminating knowledge that will advance the cause of vaccine development and implementation. We are thrilled and eager to help in sharing your research findings with the community.

\section{References}

1. Levine MM, editor. New Generation Vaccines. 4th ed. New York: Informa Healthcare; 2010.

2. Chen K, Cerutti A. Vaccination strategies to promote mucosal antibody responses. Immunity. 2010;33(4):479-491.

3. Coffman RL, Sher A, Seder RA. Vaccine adjuvants: putting innate immunity to work. Immunity. 2010;33(4):492-503.

4. Woodland DL. Jump-starting the immune system: prime-boosting comes of age. Trends Immunol. 2004;25(2):98-104

5. Poland GA. Vaccines against Lyme disease: What happened and what lessons can we learn? Clin Infect Dis. 2011;52 Suppl 3: S253-S258.

6. Omer SB, Salmon DA, Orenstein WA, deHart MP, Halsey N. Vaccine refusal, mandatory immunization, and the risks of vaccine-preventable diseases. N Engl J Med. 2009;360(19):1981-1988.
Vaccine: Development and Therapy

\section{Publish your work in this journal}

Vaccine: Development and Therapy is an international, peer-reviewed, open access journal that spans the spectrum of vaccine design and development through to clinical applications. The journal is characterized by the rapid reporting of application notes, reviews, original research and clinical studies in all therapeutic areas. Clinical outcomes, patient safety,

\section{Dovepress}

and programs for the development and effective, safe, and sustained use of vaccines will be a feature of the journal. The manuscript management system is completely online and includes a very quick and fair peer-review system. Visit http://www.dovepress.com/testimonials.php to read real quotes from published authors. 